مجتبى سليمانى ساردو' و مهدى زارعى'

1- استاديار، كروه مهندسى محيط زيست، دانشكده منابع طبيعى، دانشكاه جيرفت، (نويسنده مسوول: mojtaba.soleimani@ujiroft.ac.ir

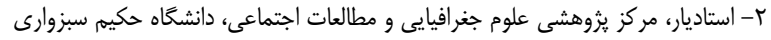

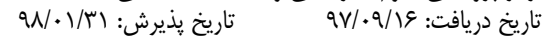

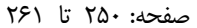

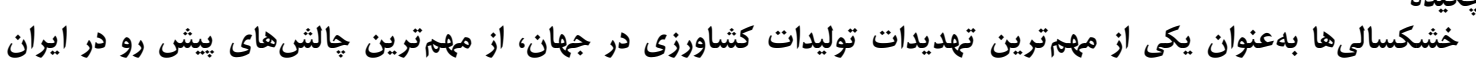

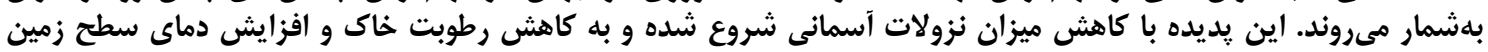

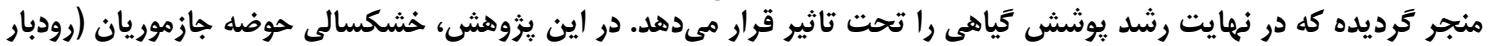

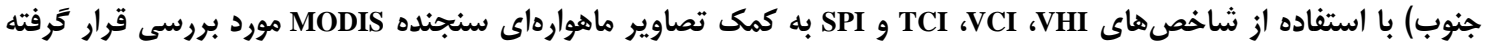

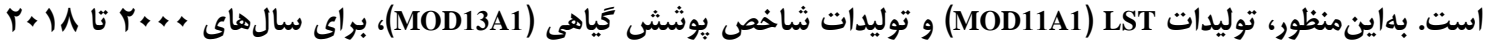

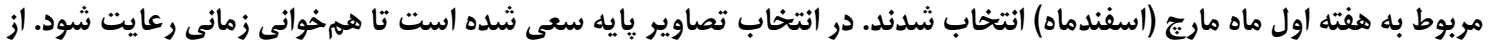

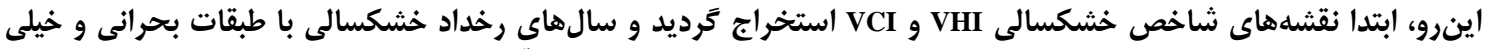

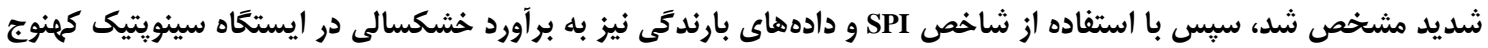

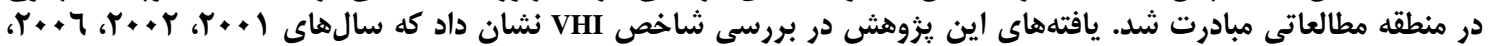

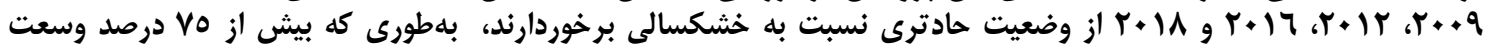

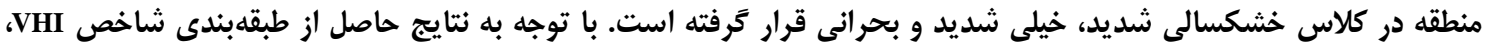

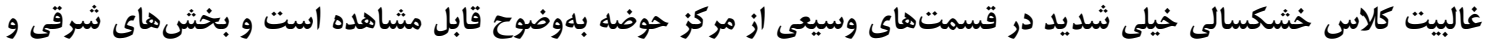

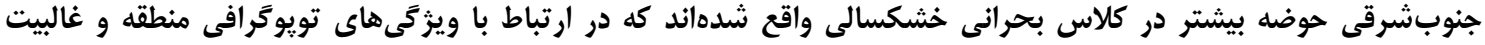

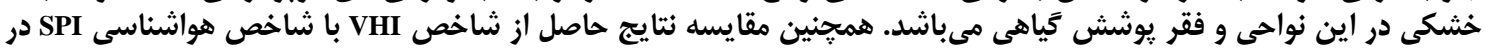

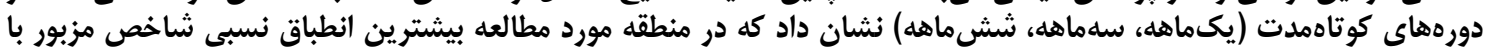

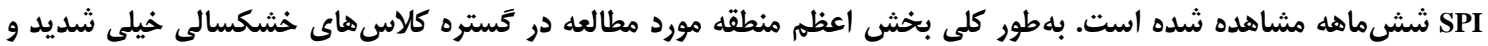

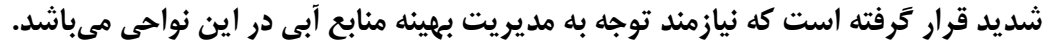

وازههاى كليدى: خشكسالى، يوشش تَياهى، VPI، SHI، جازموريان

خشكسالى رواج يافتهاند. شاخصهاى مزبور به كمك توليدات

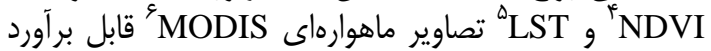
مىباشند. برخى يافتهها نشان داده است كه استفاده تلفيقى از از

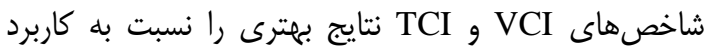

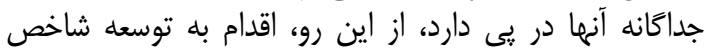

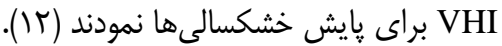

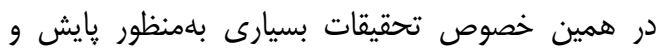

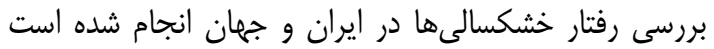

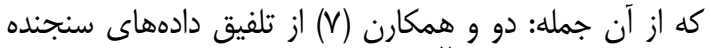

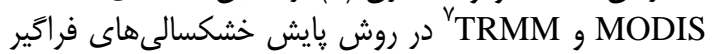

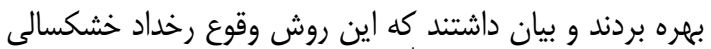

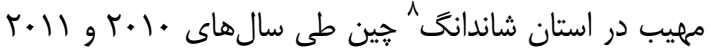

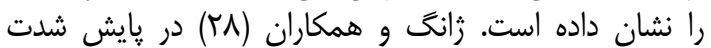

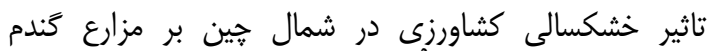

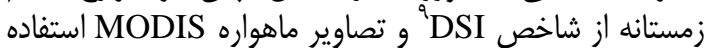

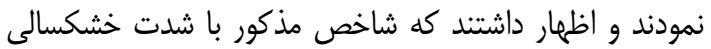

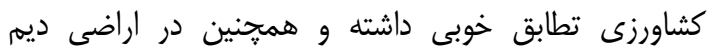

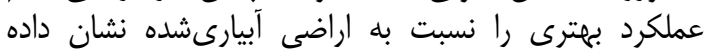

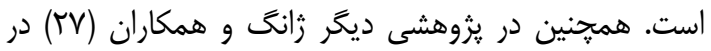

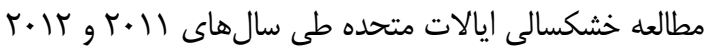

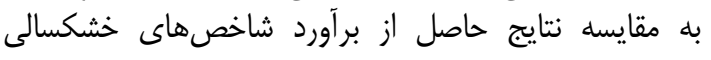

مقدمه خشكسالى بهعنوان يكى از تهديدات توليدات كشاورزى در إن إنهات

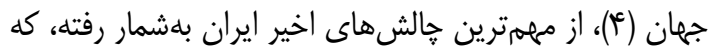

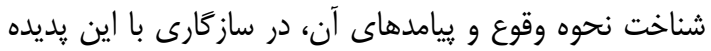

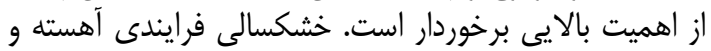

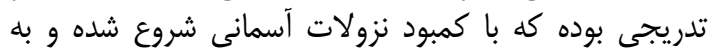

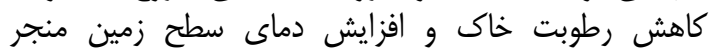

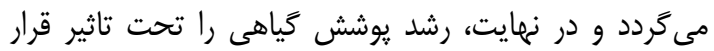

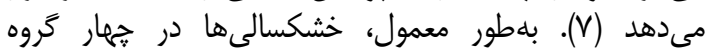

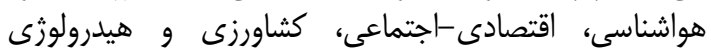

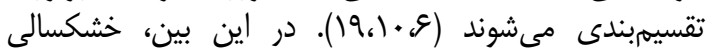

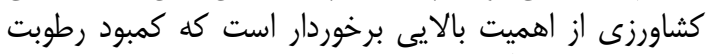

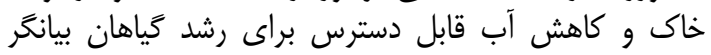
وقوع آن مى كاشاشد.

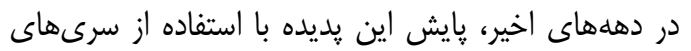

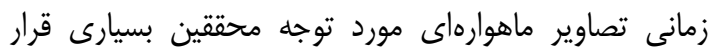

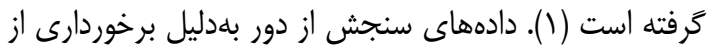

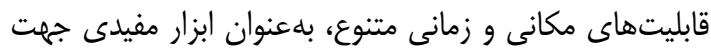

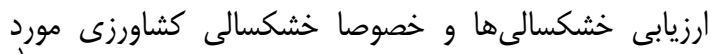

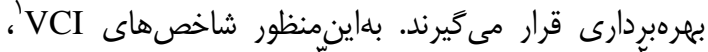
TCI 
TAI

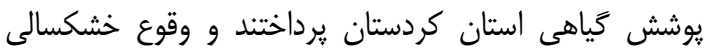

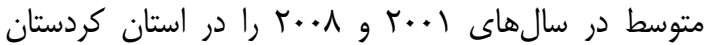

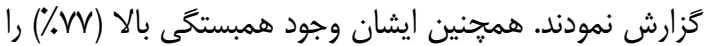

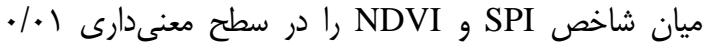
تاييد نمودند.

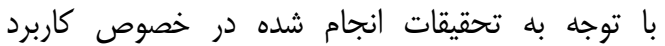

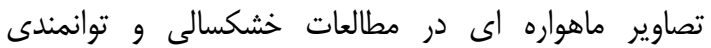

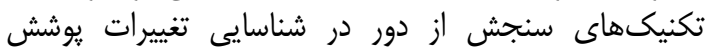

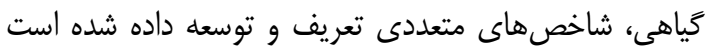

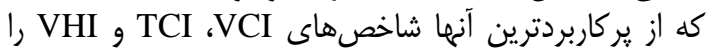

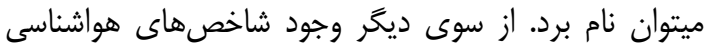

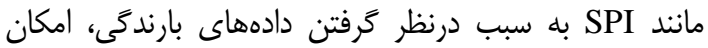

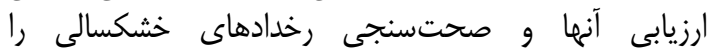

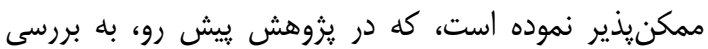

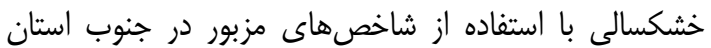
كرمان و در حوزه آبخيز جازموريان (رودبار جنوب) إنوان يرداخته

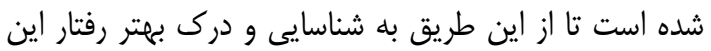

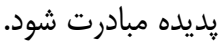

\section{مواد و روشها منطقه مورد مطالعه}

محدوده مورد مطالعه با عنوان حوزه موره آبخيز جازموريان

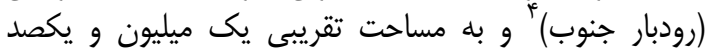
هزار هكتار، واقع در جنوب استان إنان كرمان و در در حوزه آبريز

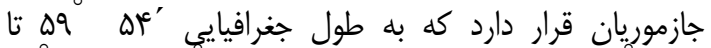

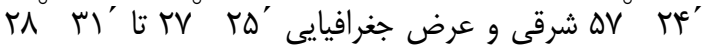

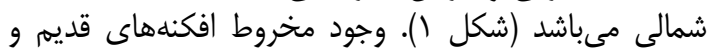

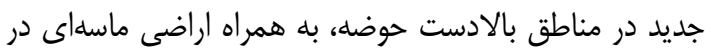

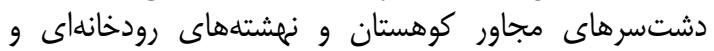

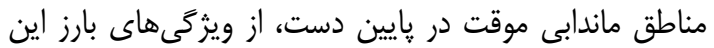

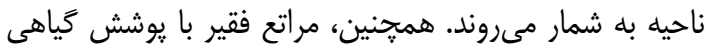

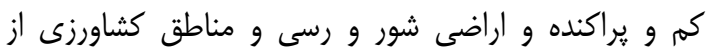

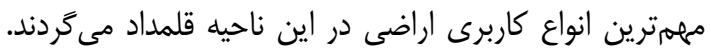

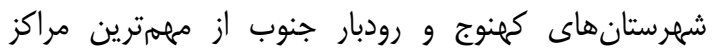
جمعيتى در اين ناحيه به شمار مى آيند.
يزوهشنامه مديريت حوزه آبخيز سال دهم/ شماره • ب/ ياييز و زمستان يوسا .

هواشناسى و كشاورزى يرداختند و بيان داشتند كه

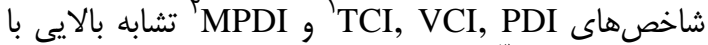

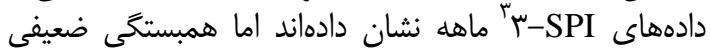

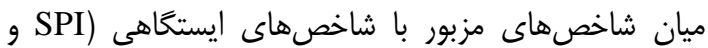
(ESPI

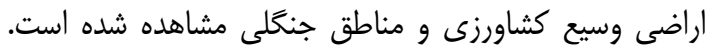

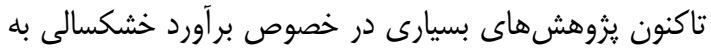

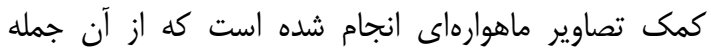

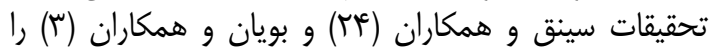

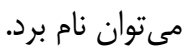

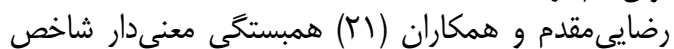
SPI با SCI

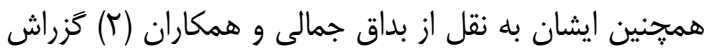

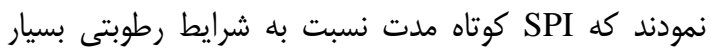

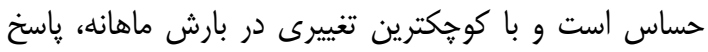

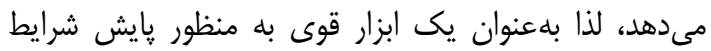

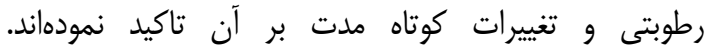

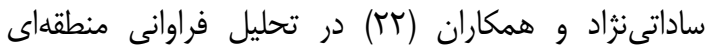

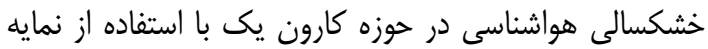
SPI شديدى رخ نداده است و وضعيت متناظر خشكسالى حداكثر

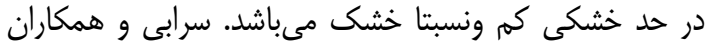

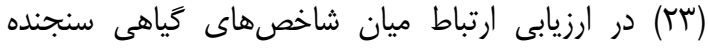
MODIS

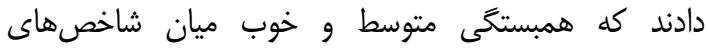

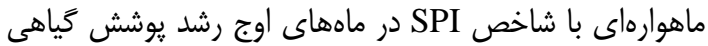

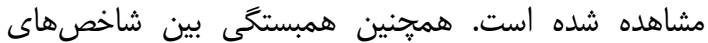

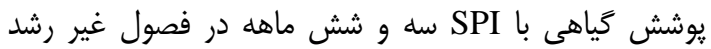

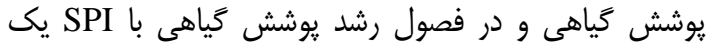

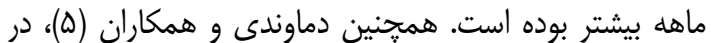

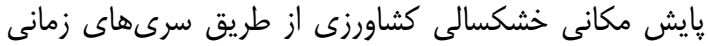

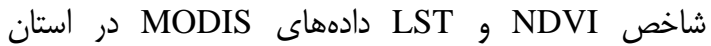

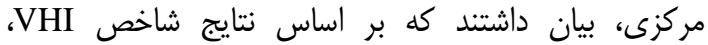

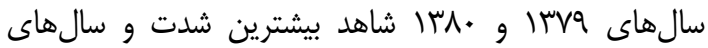

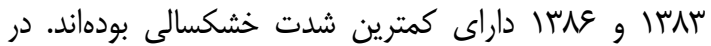

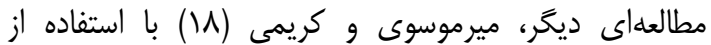

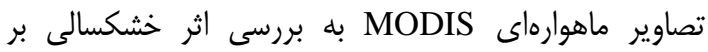




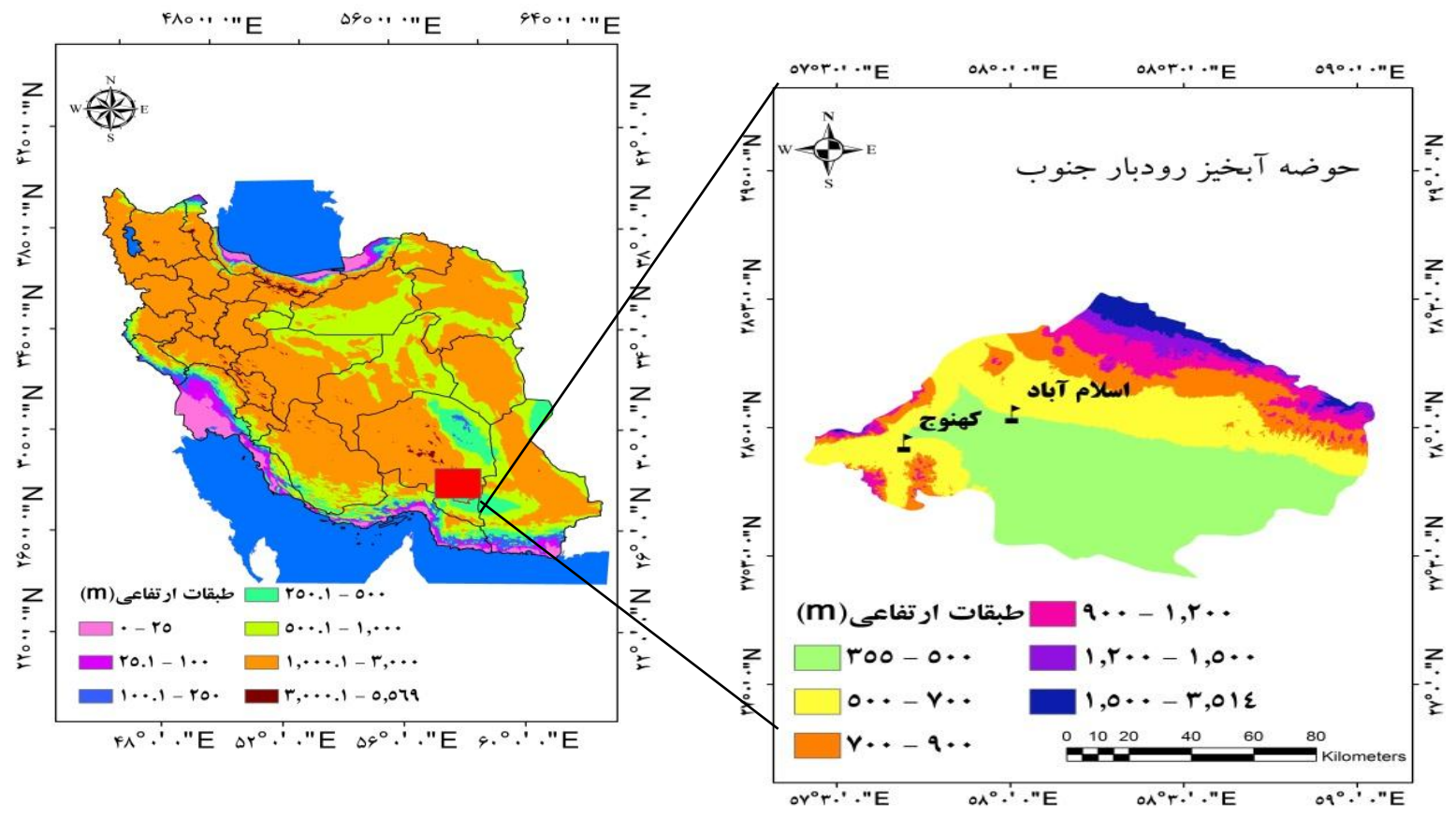

شكل ا- موقعيت جغرافيايى محدوده مطالعاتي

Figure 1. Geographic location of study area

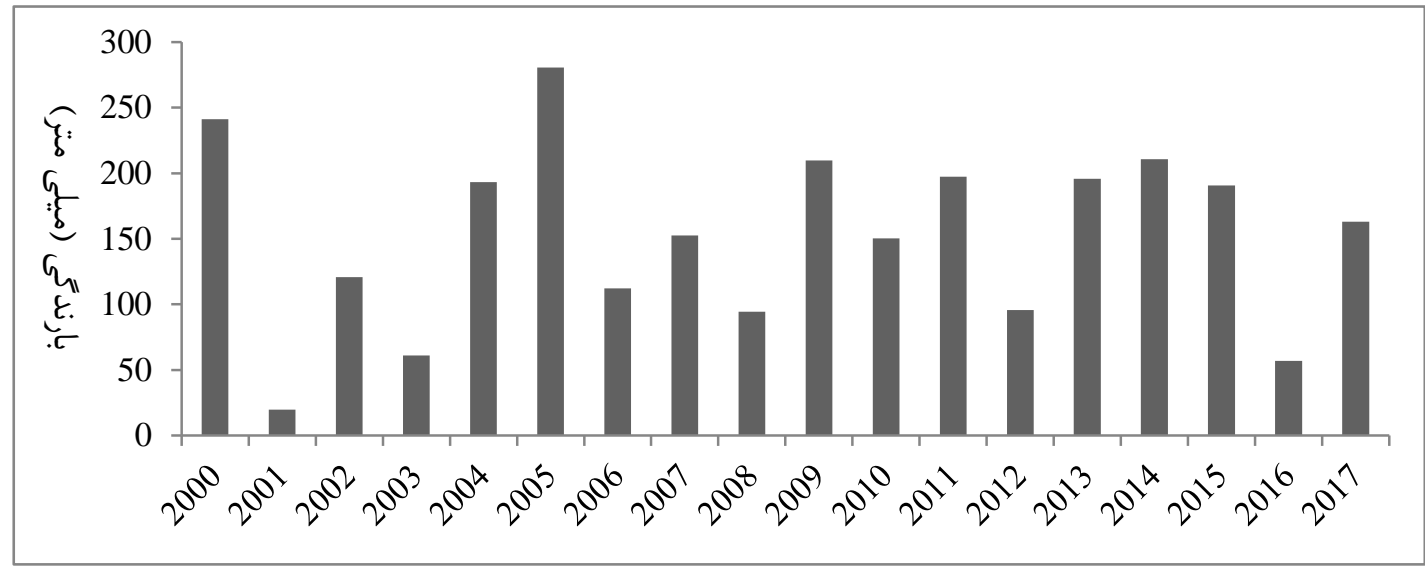

شكل r- نمودار بارندگى در ايستخاه سينويتيك كهنوج طى دوره زمانى مورد مطالعه

Figure 2. Rainfall graph at Kahnooj synoptic station during the study period

از يوشش كياهى مىباشند. شاخص NDVI به عنوان يكى از

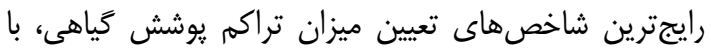

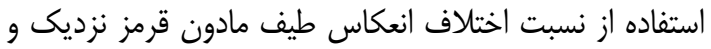

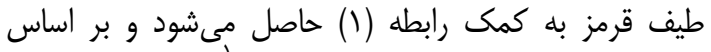
مقادير بين ا- تا ا+ ارزش كذارى مى شود'.

$\mathrm{NDVI}=\frac{\mathrm{NIR}-\mathrm{Red}}{\mathrm{NIR}+\mathrm{Red}}$

كه در آن NIR انعكاس باند مادون قرمز نزديك و Red ماندين

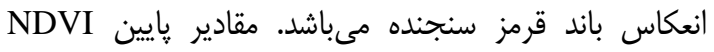

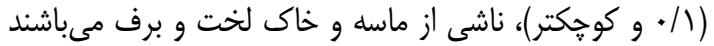

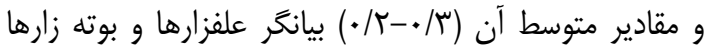

\section{روش تحقيق}

به منظور ايجاد سرىهاى زمانى، توليدات شاخصهاى كياهى NDVI و LST تصاوير سنجنده

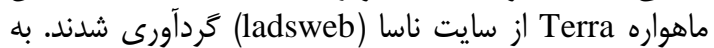

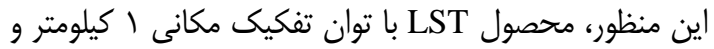

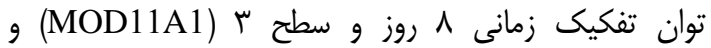
توليدات شاخص :وشش تيان زياهى (MOD13A1)

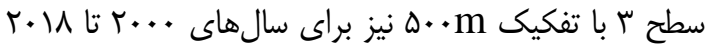

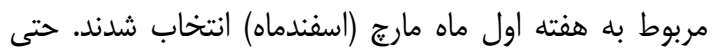

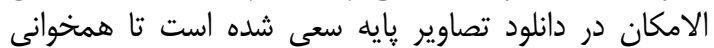

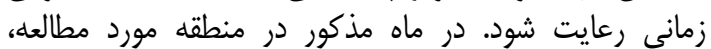
كياهان مرتعى در مرحله رويش و اراضى كشاور درانى منى نيز يوشيده 
مطلوبترى مىباشد. شاخص مزبور با استفاده از رابطه زير

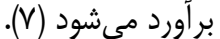

\section{$\mathrm{TCI}=\frac{L S T \max -L S T}{L S T \max -L S T \min }$}

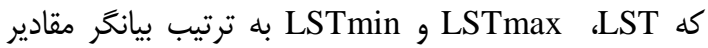
شاخص، حداكثر و حداقل ارزشهاى هر ريبكسل مىباشد.

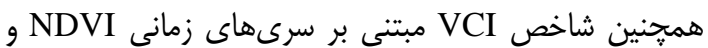

طبق رابطه زير برآورد مى گردد (ب (I):

$\mathrm{VCI}=100 \times \frac{N D V I-N D V I \min }{N D V I \max -N D V I \min }$

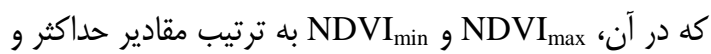
حداقل NDVI مئل

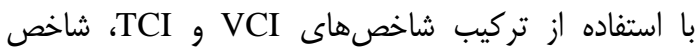

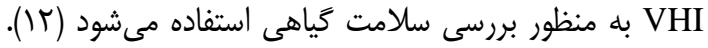

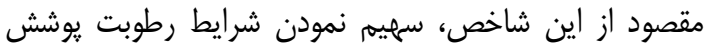

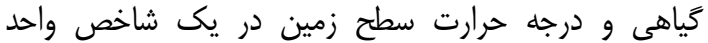

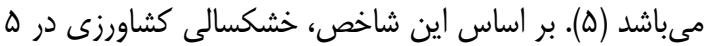

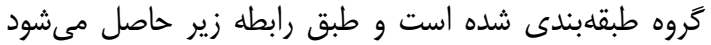

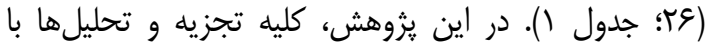

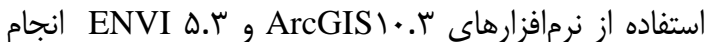

$\mathrm{VHI}=0.5(\mathrm{VCI})+0.5(\mathrm{TCI})$

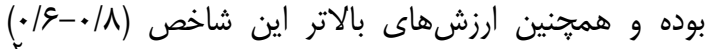

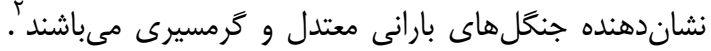

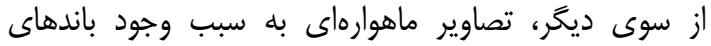

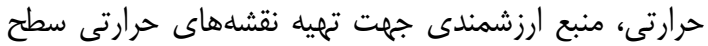

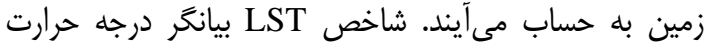

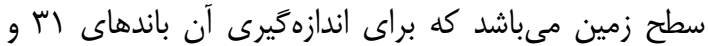

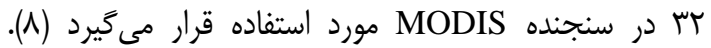
تغييرات مقادير LST در طول روز در داخل تصوير برحسب دورد

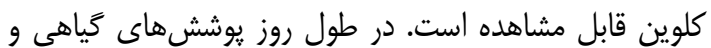

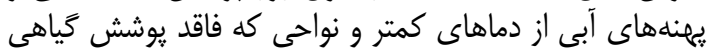

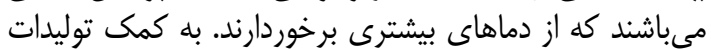

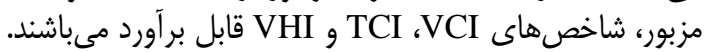
شاخص هزاى TCI ، TCI و

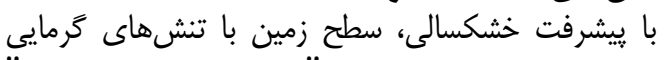

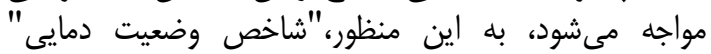

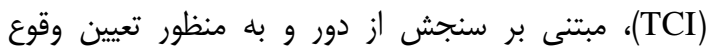

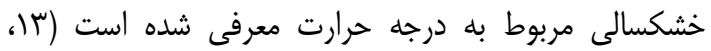

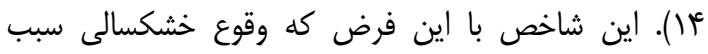

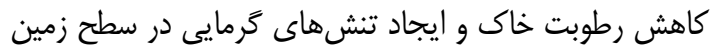

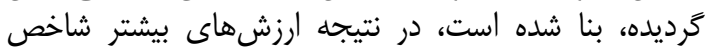
LST

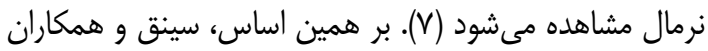

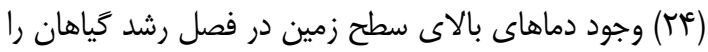

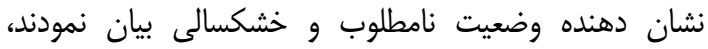

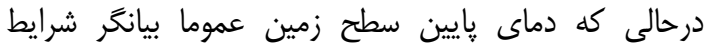

جدول I- طبقات خشكسالى كشاورزى بر اساس شاخصهاى VHI و VCI (צr) Table 1. Agricultural drought classification based on the VHI \&VCI

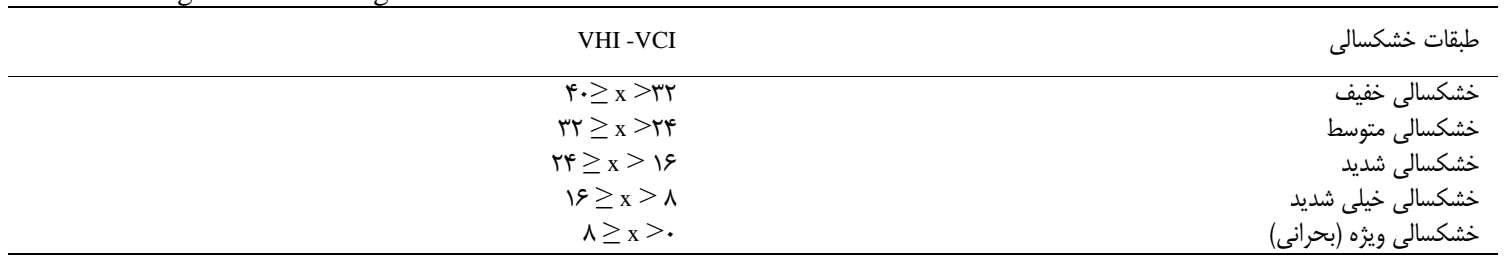

با مقياس هاى زمانى مختلف، ممكن نموده است (9). مقادير

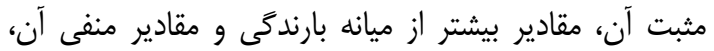

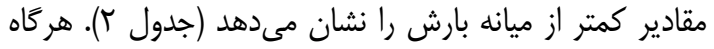

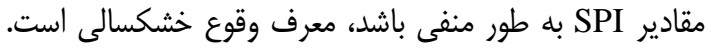

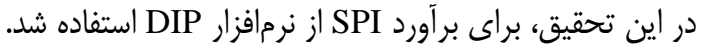

شاخص SPI در اين يزوهش بـ به منظور برآورد خشكسالى هواشناسى در

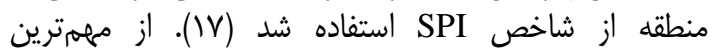

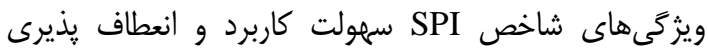

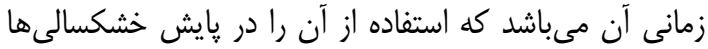

جدول r (IV) SPI جبقهبندى خشكسالى بر اساس طبقهبندى

Table 2. Drought classification based on the SPI وضعيت خشكسالى

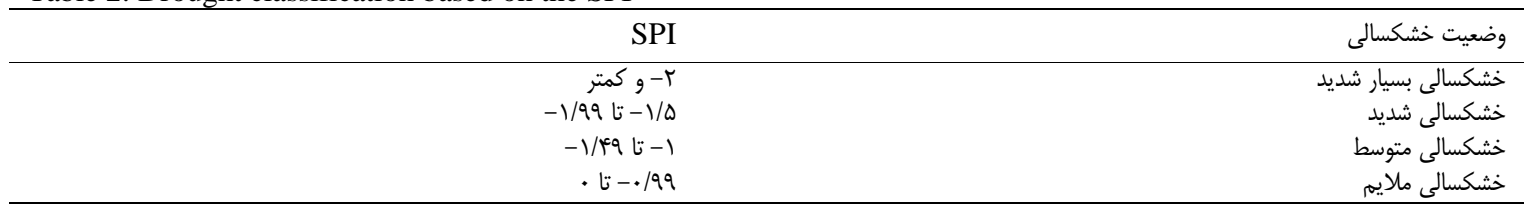


نامطلوب مىباشد. همانطور كه نقشههاى حاصل از شاخص

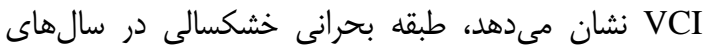
1.

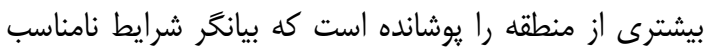

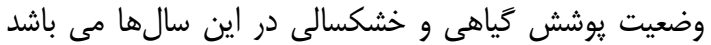

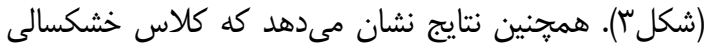

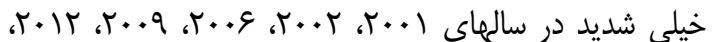

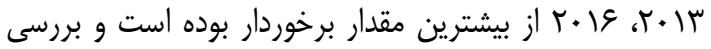

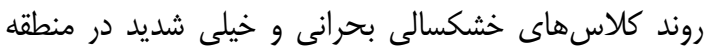

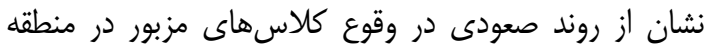
مورد مطالعه در ساليان اخير مىدهد (شكل عاء).
نتايج و بحث

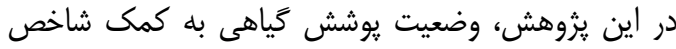

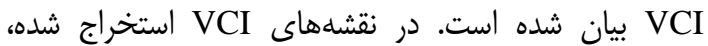

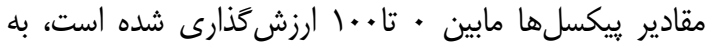

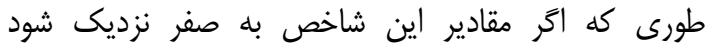

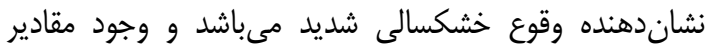

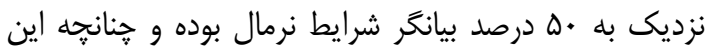

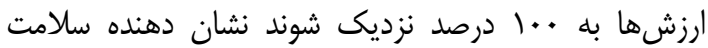

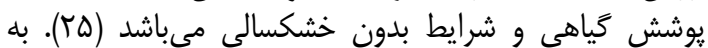

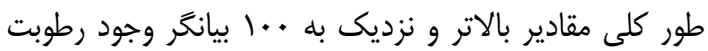

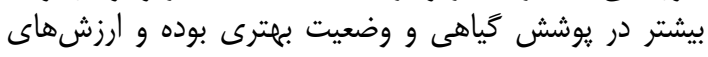

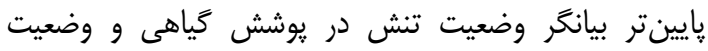

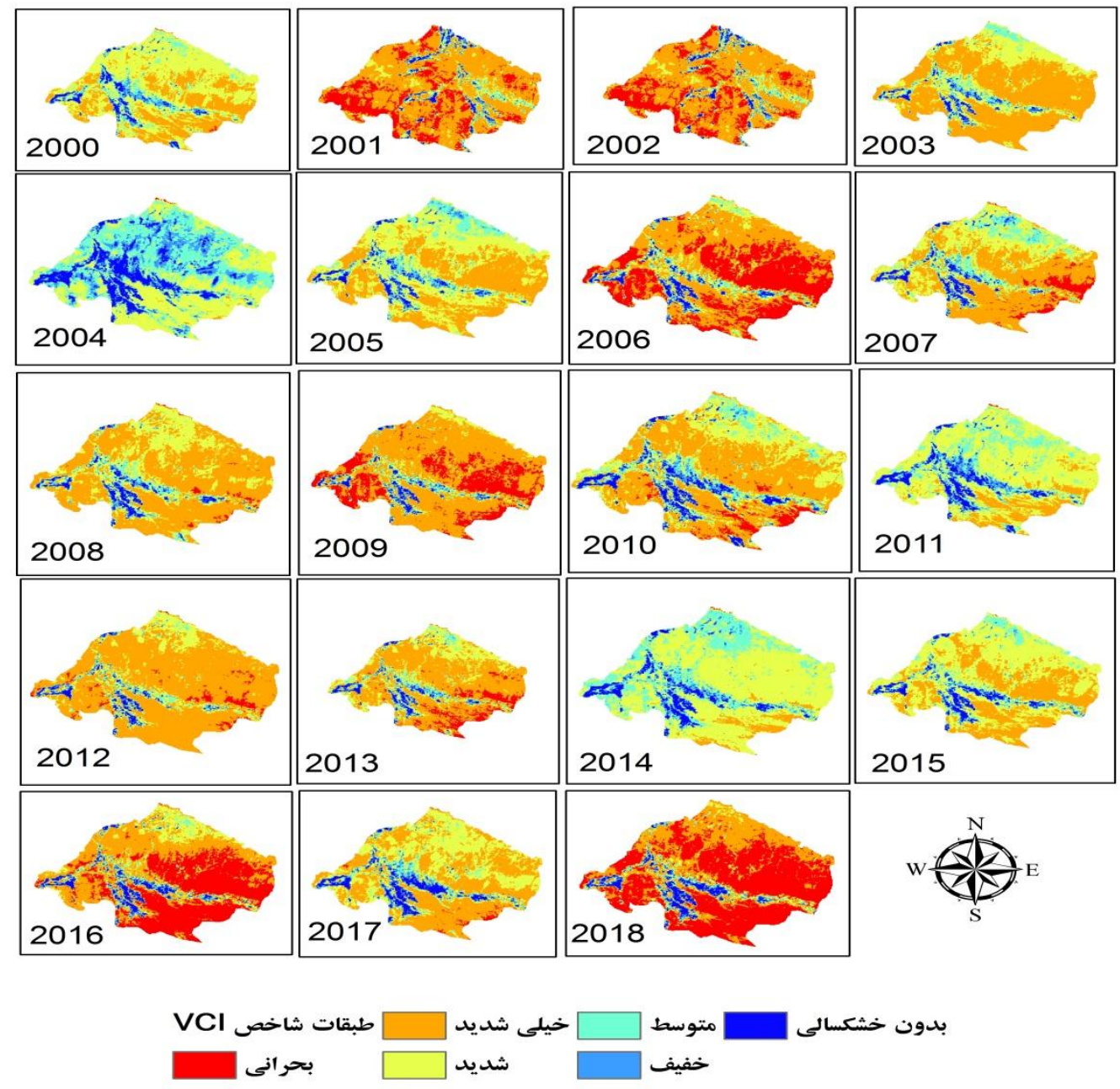

شكل r- وضعيت خشكسالى براساس شاخص VCI

Figure 3. Drought condition based on the VCI index 


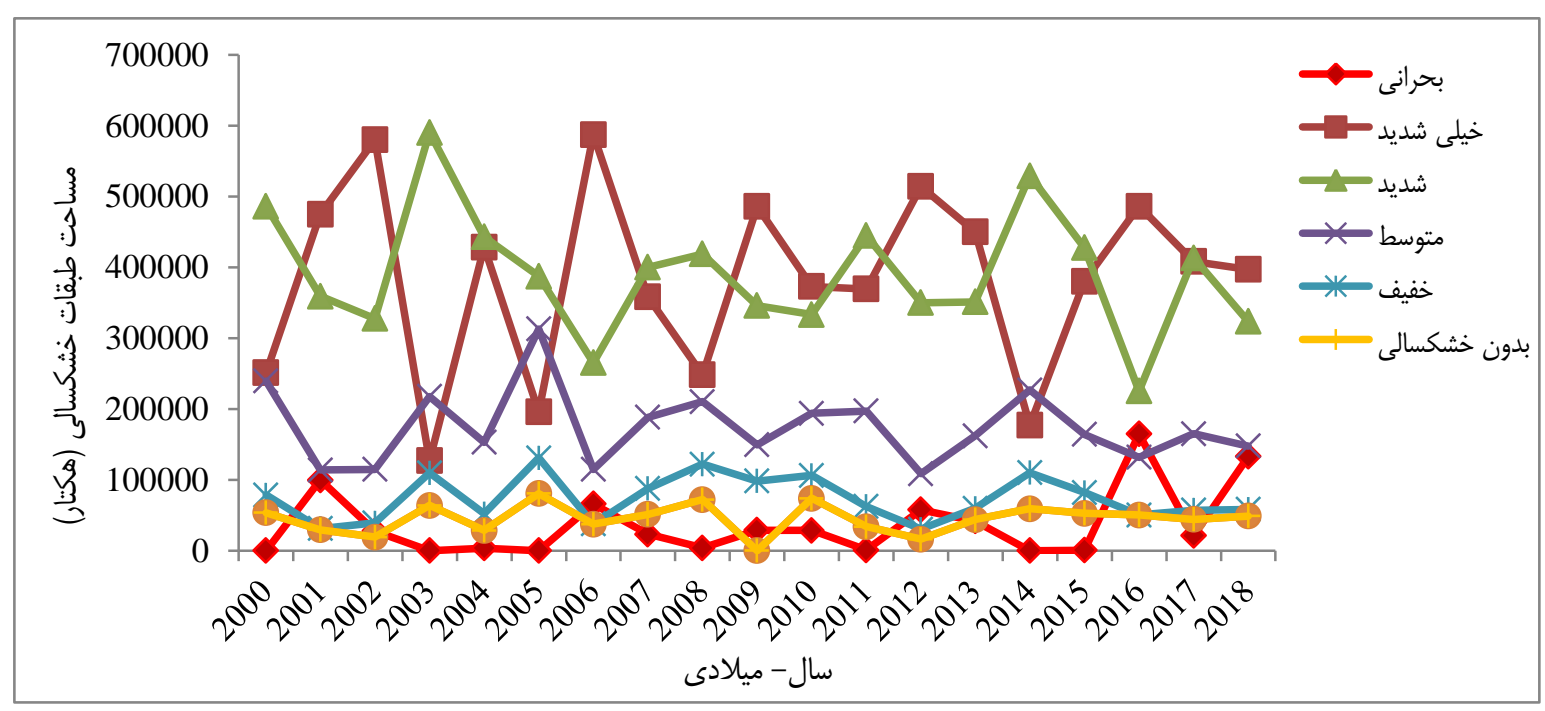

شكل عا - روند رخداد انواع كلاس هاى خشكسالى در محدوده مورد مطالعه بر اساس شاخص DCI ل Figure 4. Drought classes' trend based on the VCI index

حوضه بيشتر در كلاس بحرانى خشكسالى نمايان شدهاند كه

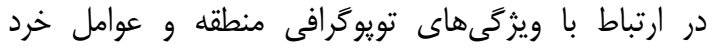

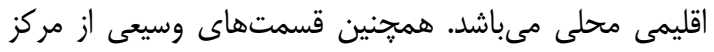

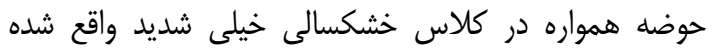

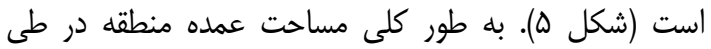

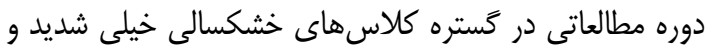
شديد قرار گرفته است.
بررسى شاخص VHI طى دوره زمانى 19 ساله در منطقه

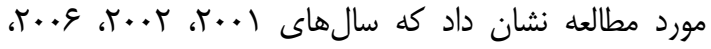

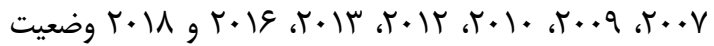

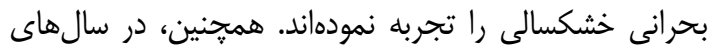

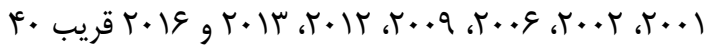
تا •ه درصد از مساحت منطقه در كلاس خشكسالى خيلى خلى

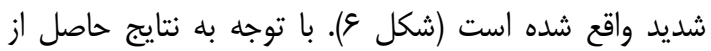

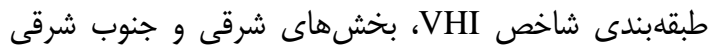



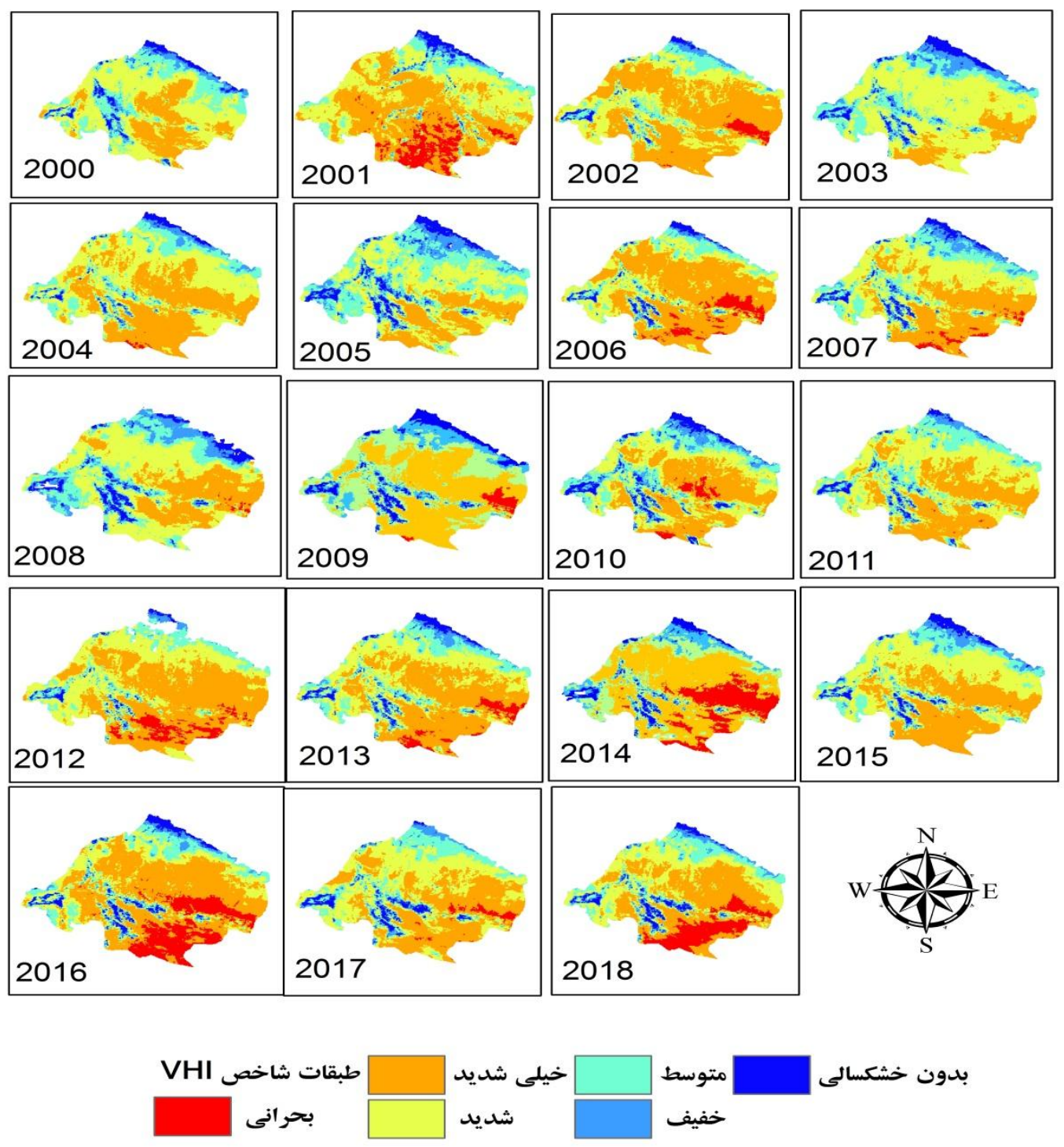

شكل ه- وضعيت خشكسالى كشاورزى براساس شاخص DHI

Figure 5. Drought condition based on the VHI index 


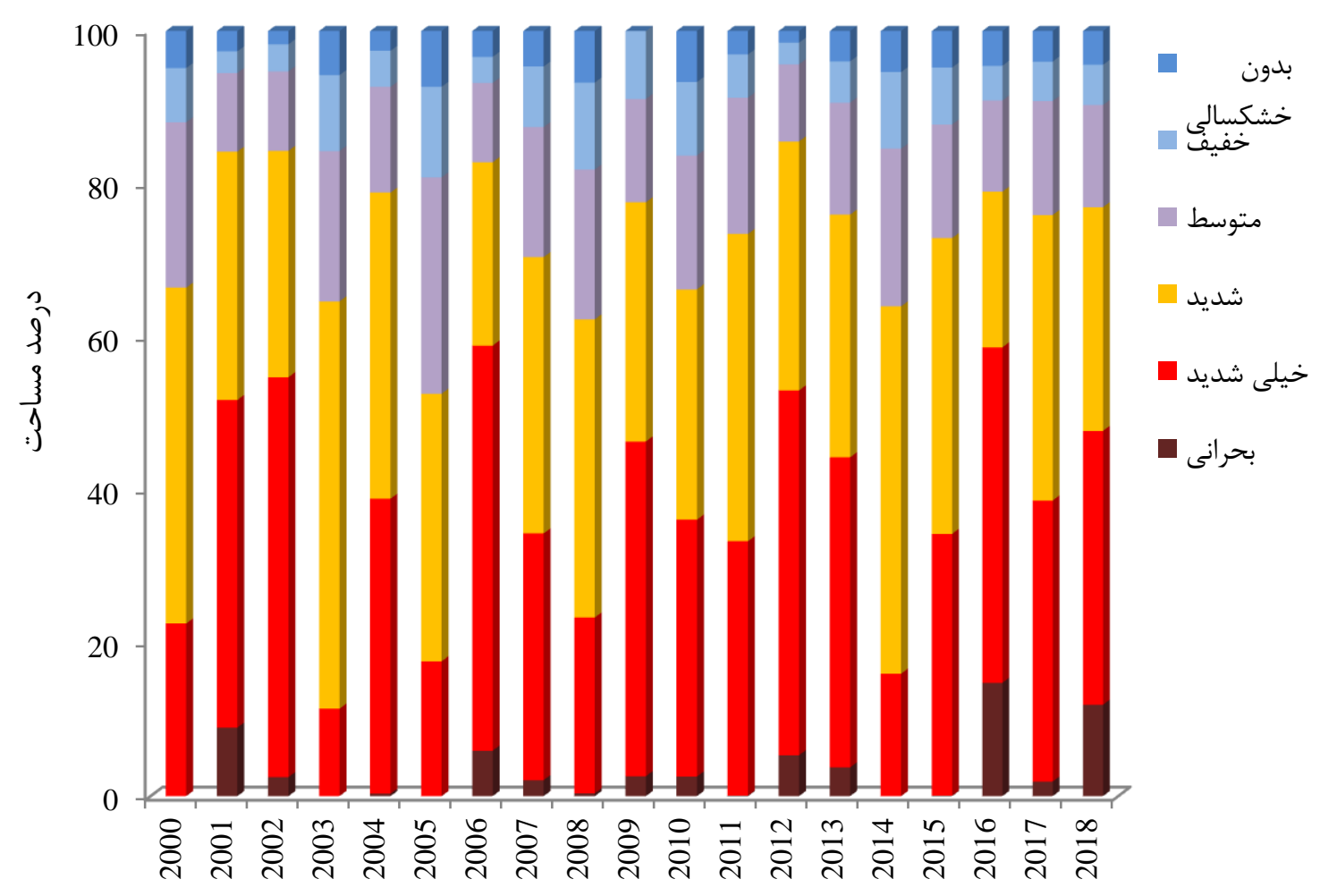

شكل و- توزيع درصد مساحت طبقات مختلف خشكسالى بر اساس شاخص OHI

Figure 6: Percentage of different drought classes based on the VHI index

برآورد شد. بر اساس يافتههاى تحقيق، همانطور كه بررسى رونى

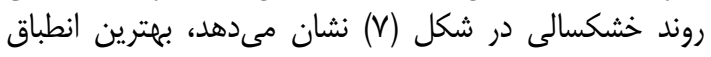

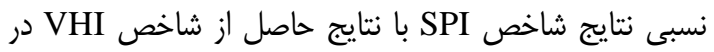

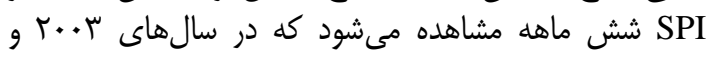

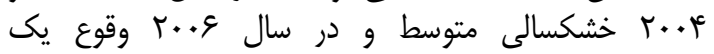
خشكسالى خيلى شديد را نشان داده است.
بررسى خشكسالى در ايستخاههاى سينويتيك منطقه با

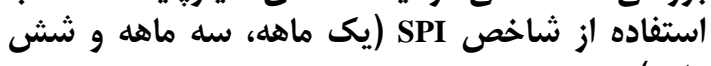
ماهد) در تحقيق حاضر، دادههاى ايستخاه سينويتيك كهنوج در آنران

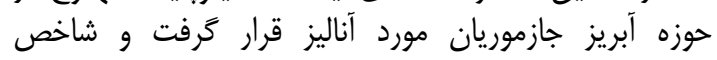

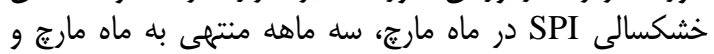

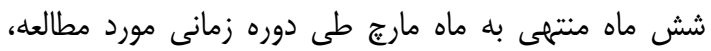



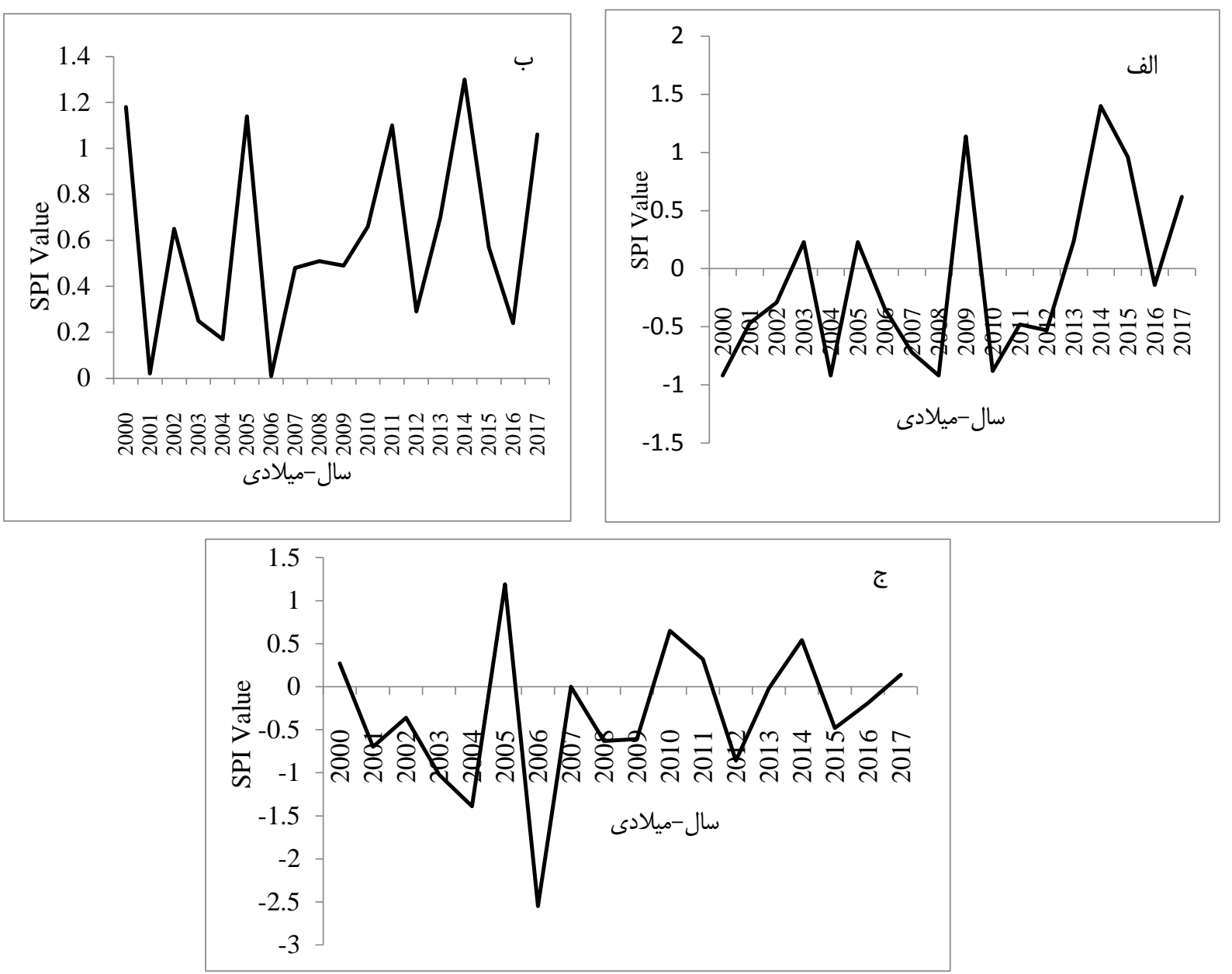

شكل V- طبقهبندى خشكسالى در محدوده مورد مطالعه بر اساس شاخص SPI كوتاه مدت (الف: (ماهله، ب: سٓماهل، ج: عماهه)

Figure 7. Drought classification based on the short-term SPI index (A: 1 month, B: 3 months, C: 6 months)

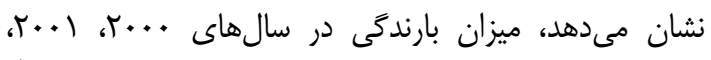
j tr

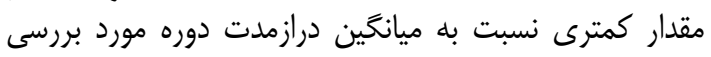

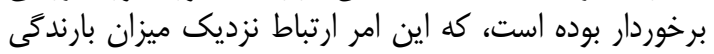

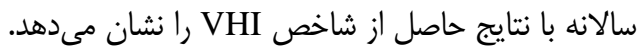

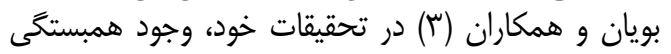

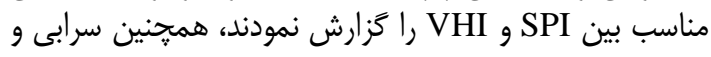

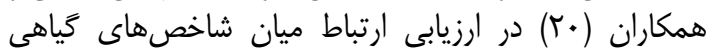

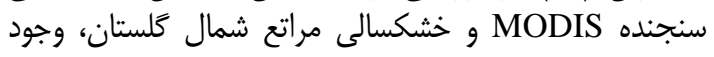

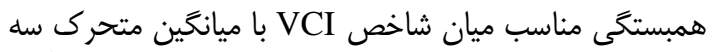

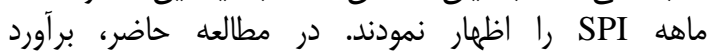

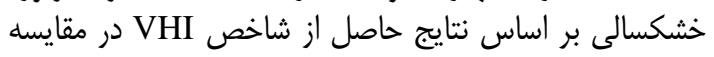

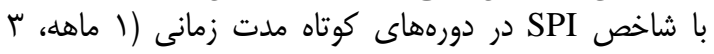

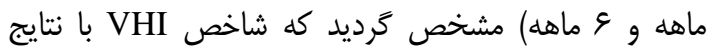

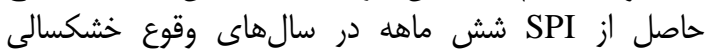

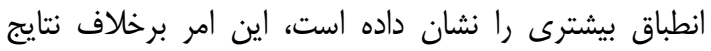

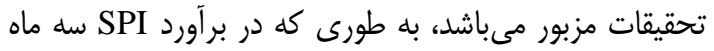

در قاسخ به تنشهاى محيطى و شرايط خشكى، بازخورد

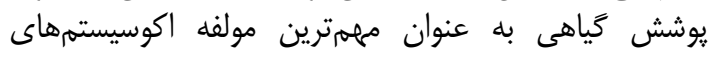

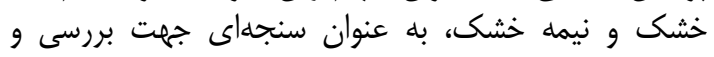

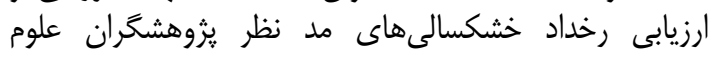

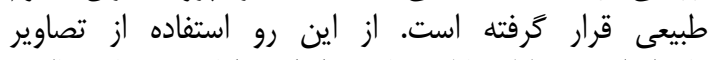

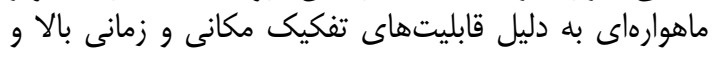

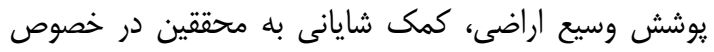

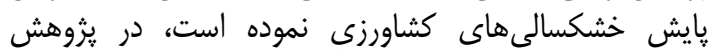

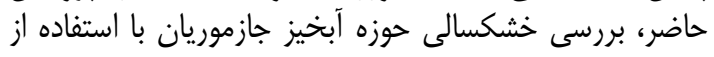

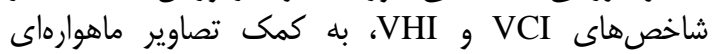

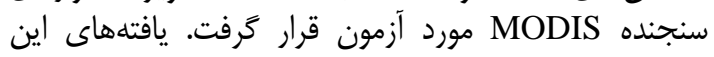

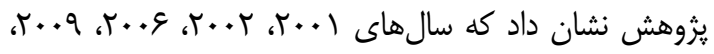

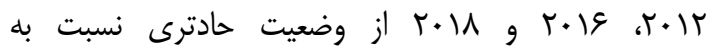

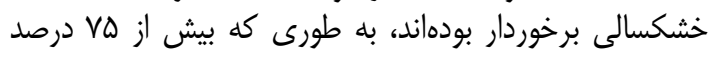

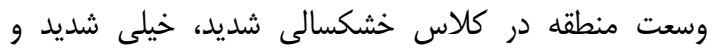

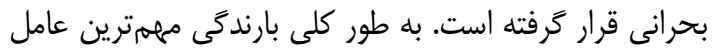

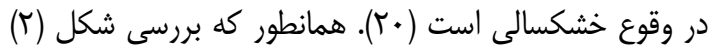


نزديك اين شاخصها با ميزان بارندگى در هر منطقه را نشان

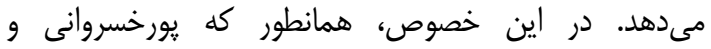

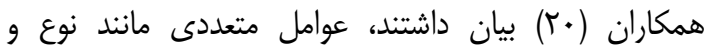

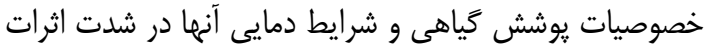

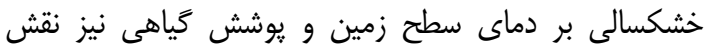
دارند.

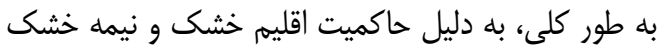

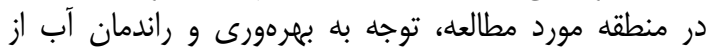

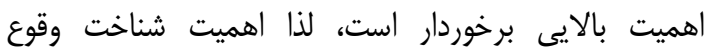

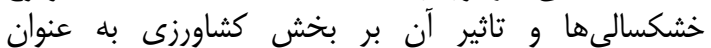

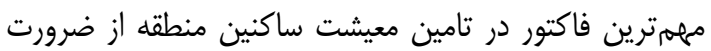

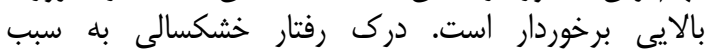

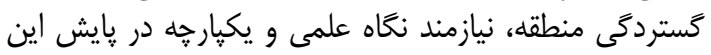

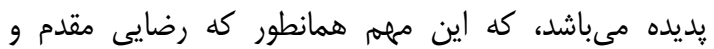

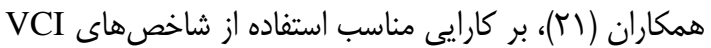

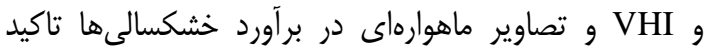

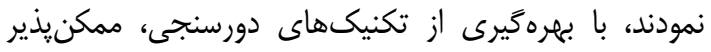

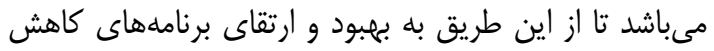
اثرات خشكسالى مبادرت شود.

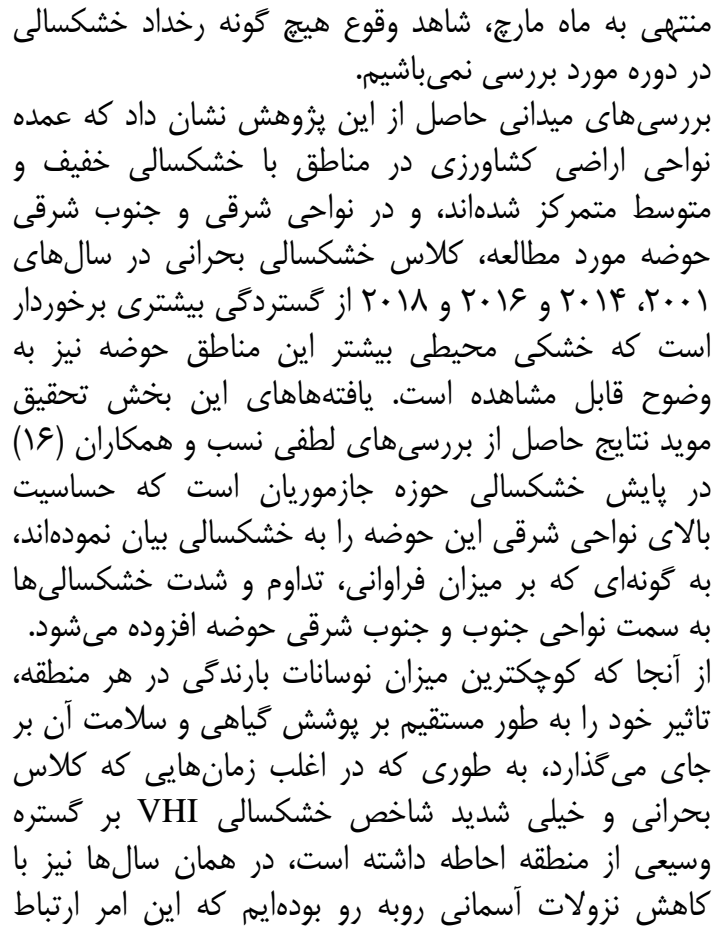

منابع

1. AghaKouchak, A., A. Farahmand, F.S. Melton, J. Teixeira, M.C. Anderson, B.D. Wardlow and C.R. Hain. 2015. Remote sensing of drought: progress, challenges and opportunities. Reviews. Geophysics, 53:452-480. doi.org/10.1002/2014RG000456.

2. Badaq Jamali J., M Asiaee, S. Samadi Naghab and S. Javanmard. 2005. Drought risk management (knowledge and solutions). Sokhan Gostar press (In Persian).

3. Bhuiyan, C., R.P. Singh and F.N. Kogan, 2006. Monitoring drought dynamics in the Aravalli region (India) Using Different Indices Based on Ground and Remote Sensing Data. International Journal of Applied Earth Observation and Geoinformation, 8: 289-302.

4. Campbell, B.M., S.J. Vermeulen, P.K. Aggarwal, C. Corner-Dolloff, E. Girvetz, A.M. Loboguerrero, J. Ramirez-Villegas, T. Rosenstock, L. Sebastian, P.K. Thornton and E. Wollenberg. 2016. Reducing risks to food security from climate change. Global Food Ssecurity, 11: 34-43. https://doi.org/10.1016/j.gfs.2016.06.002

5. Damavandi, A., M. Rahimi, M.R. Yazdani and A.A. Noroozi. 2016. Spatial monitoring of agricultural drought through time series of NDVI and LST indices of MODIS data (case study: Markazi Province). Scientific-Research Quarterly of Geographical Data (SEPEHR), 25(99):115-126 (In Persian).

6. Dracup, J.A., K.S. Lee and E.G. Paulson Jr. 1980. On the statistical characteristics of drought events. Water Resource Research, 16: 289-296.

7. Du. L., T. Qingjiu, Y. Tao, Q. Meng, T. Jancso, P. Udvardy and Y. Huang. 2013. A comprehensive drought monitoring method integrating MODIS and TRMM data. International Journal of Applied Earth Observation and Geoinformation, 23: 245-253.

8. Farahani, F., T. Farahnaz, M. Hatami and E Owlad. 2014. Identification of thermal anomalies in Saravan earthquake based on Satellite Image Processing. 16th Iranian Geophysical Conference, 203208 (In Persian).

9. Guttman, N.B. 1999. Accepting the standardized precipitation index: a calcula-tion algorithm. Journal of the American water resources Association, 35(2): 311-322.

10. Heim, R.R. 2002. A review of twentieth-century drought indices used in the United States. Bulletin of the American Meteorological Society, 83(8): 1149-1166.

11. Kogan, F. 2002. World droughts in the new millennium from AVHRR-based vegetation health indices. EOS, Transactions, American Geophysical Union, 83(48): 557-563.

12. Kogan, F., N. Stark, A. Gitelson, L. Jargalsaikhan, C. Dugrajav and S. Tsooj. 2004. Derivation of pasture biomass in Mongolia from AVHRR-based vegetation health indices. International Journal of Remote Sensing, 25(14): 2889-2896.

13. Kogan, F.N. 1995. Droughts of the late 1980s in the United States as derived from NOAA polarorbiting satellite data. Bulletin of the American Meteorological Society, 76(5): 655-668. 
14. Kogan, F.N. 1995. Application of vegetation index and brightness temperature for drought detection. Advances in Space Research, 15(11): 91-100 .

15. Liu, W. and F.N. Kogan. 1996. Monitoring regional drought using the Vegetation Condition Index. International. Journal of Remote Sensing. 17: 2761-2782.

16. Lotfi Nasab, S., A. Gohar Dost and M. Khosroshahi. 2018. Assessment and Application of Geostatistics in Identifying and Analyzing Drought Characteristics of Jazmourian Watershed. Journal of Watershed Management Research, 10(18): 12-25 (In Persian).

17. Mckee, T.B., N.J. Doesken and J. Kleist 1993. The relationship of drought frequency and duration to time Scales. Preprints 8th Conference on Applied Climatology, 179-184.

18. Mirmosavei, H. and H. Kareimei. 2013. Effect of drought on vegetation cover using MODIS sensing images case: Kurdistan Province. Geography and Development Iranian Journal, 11(31): 57-76.(In Persian)

19. Orville, H.D. 1990. AMS statement on meteorological drought. American Meteorological Society. 45 Prepared by the AMS Committee on Applied Climatology.

20. Pourkhosravani, M., A. Mehrabi and S.H. Mousavi. 2018. Drought spatial analysis of Sirjan basin using remote sensing. Desert Ecosystem Engineering Journal, 7(20):13-23.

21. Rezaeimoghadam M., K. Khalil Valizadeh, H. Rostamzadeh and A. Rezaee. 2012. Evaluating the Adequacy of MODIS in the Assessment of Drought (Case Study: Urmia Lake Basin). Geography and Sustainability of Environment, 2(5): 37-52 (In Persian).

22. Sadatinejad, S.J., S.H. Alavinia, R. Abedi, A. Honarbakhsh and KH. Abdollahi. 2015. Frequency analysis of regional meteorological drought in Karun-1 basin of Iran. Journal of Watershed Management Research, 6(12): 108-117.

23. Sarabi, S., A. Heshmatpour, B. Komaki and A. Tahmasebi. 2015. Relationship between MODIS vegetation indices and drought in northern rangelands of Golestan province. Iranian Journal of Range and Desert Research, 22(2): 392-405 (In Persian).

24. Singh, R.P., S. Roy and F. Kogan. 2003. Vegetation and temperature condition indices from NOAA AVHRR data for drought monitoring over India. International Journal of Remote Sensing, 24(22): 4393-4402.

25. Thenkabail, P.S., M.S.D.N. Gamage and V.U. Smakhtin. 2004. The use of remote sensing data for drought assessment and monitoring in Southwest Asia. Research Report 85, International Water Management Institute.

26. Yagci, A.L., L. Di, M. Deng, W. Han and Ch. Peng. 2011. Agricultural drought monitoring from space using freely available MODIS data and impacts on cotton commodity .Pecora 18 - Forty Years of Earth Observation. Understanding a Changing World, November 14-17, 2011. Herndon, Virginia.

27. Zhang, L., W. Jiao, H. Zhang, Ch. Huang and Q. Tong. 2017. Studying drought phenomena in the Continental United States in 2011 and 2012 using various drought indices. Remote Sensing of Environment, 190: 96-106.

28.Zhang, J., Q. Mu and J. Huang. 2016. Assessing the remotely sensed Drought Severity Index for agricultural drought monitoring and impact analysis in North China. Ecological Indicators, 63: 296309. 


\title{
Drought Monitoring Using MODIS Data and Its Comparison with SPI Meteorological Index in Short Periods (Case Study: Jaz_Murian basin)
}

\author{
Mojtaba Soleimani Sardo, Mahdi Zarei \\ 1- Assistant Professor, Department of Environmental Science and Engineering, Faculty of Natural \\ Resources, University of Jiroft, Iran \\ 2- Assistant Professor, Research Center of Social Studies \& Geographical Sciences, Hakim Sabzevari \\ University, Iran \\ Received: December 7, 2018 \\ Accepted: April 20, 2019
}

\begin{abstract}
Drought is one of the most important threats for agricultural production in the world, espatially in Iran. This phenomenon has started with reduction of precipitations that lead to a decrease in soil moisture and an increase in soil surface temperature, which affect the vegetation growth. The purpose of this study was to investigate droughts in the Jaz_Murian basin by VHI, VCI, TCI and SPI indices using MODIS satellite imagery and meteorological data. For this purpose, the LST products (MOD11A1) and vegetation products (MOD13A1) were selected from 2000 to 2018 at the same time (the first week of March). The VHI and VCI maps were produced and the drought occurrences with critical and very severe classes were identified. Also, the SPI index was calculated using precipitation data in Kahnooj synoptic meteorological station. According to the VHI index, the results showed that over $75 \%$ of the study area was classified as the severe, very severe and extreme classes of drought and has suffered from drought in 2001, 2002, 2006, 2009, 2012, 2016 and 2018. Very severe and extreme classes are covered the center of the region, and the eastern and southeastern parts of the basin that likely is related to the rainfall reduction and topographic characteristics of the area and poor vegetation. In comparison with the SPI meteorological index in the short periods (one month, three months, six months), the VHI index indicates the more correlation with the six-month SPI. According to the results obtained from this study, a large part of the study area is located in severe and very severe of drought classes which need more attention to water resource management in this region.
\end{abstract}

Keywords: Drought, Vegetation Cover, VHI, SPI, Jaz_Murian 